ENTREPRENEURSHIP AND SUSTAINABILITY ISSUES

ISSN 2345-0282 (online) http://jssidoi.org/jesi/

2020 Volume 7 Number 3 (March)

http://doi.org/10.9770/jesi.2020.7.3(3)

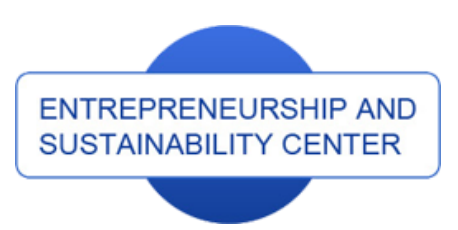

Publisher

http://jssidoi.org/esc/home

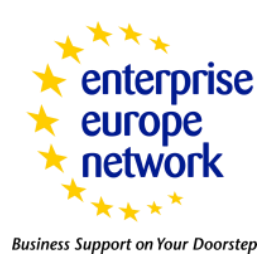

CASPA

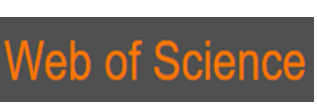

1) Clarivate

Analytics

\title{
INITIAL COIN OFFERINGS (ICOs): BENEFITS, RISKS AND SUCCESS MEASURES
}

\author{
Alfreda Šapkauskienė ${ }^{1}$, Ingrida Višinskaitė ${ }^{2}$ \\ ${ }^{1,2}$ Kaunas University of Technology, School of Economics and Business, K. Donelaičio g. 20, Kaunas, Lithuania \\ ${ }^{1}$ Vilnius University, Faculty of Economics and Business Administration, Sauletekio al. 9, Vilnius, Lithuania \\ E-mails: ${ }^{1}$ alfreda.sapkauskiene@evaf.vu.lt; ${ }^{2}$ ingrida.visinskaite@ktu.edu
}

Received 17 September 2019; accepted 18 January 2020; published 30 March 2020

\begin{abstract}
The initial coin offering is usually defined as a new, innovative way of raising funds used by organizations, companies, or entrepreneurs, attracting funds through a cryptographic exchange in exchange for the coins that can be sold, used for future products or services purchase or profit. This article provides an overview of the evolving ICO market and indicates the main advantages and risks of the ICO. It is pointed out that ICO offers many advantages, such as high liquidity, return on investment, availability, fast capital raising process, minimization of capital raising costs. Nonetheless, the noticeable benefits of ICOs are often available only when companies or investors agree to take considerable risks, caused by the information asymmetry, lack of investor protection, proper regulation and methodical guidance both for investors and entrepreneurs. Considering the novelty, volatility, emerging risks, growing popularity of the ICO market and the lack of research in the scientific literature, it is important to investigate the factors that influence the success of the ICO, which is usually defined as the amount of funds attracted, listing of the coins, return on investment, market capitalization or the duration of the ICO.
\end{abstract}

Keywords: Initial Coin Offering; ICO; Token; Blockchain; Cryptocurrencies; Diversification; FinTech; Open Innovation

Reference to this paper should be made as follows: Sapkauskiene, A., Visinskaite, I. 2020. Initial Coin Offerings (ICOs): Benefits, Risks and Success Measures. Entrepreneurship and Sustainability Issues, 7(3), 1472-1483. https://doi.org/10.9770/jesi.2020.7.3(3)

JEL Classifications: G15, G24, O31, L26

\section{Introduction}

The initial coin offering (ICO) is usually defined in the literature as a new, innovative way of raising funds used by organizations, companies, or entrepreneurs, attracting funds through a cryptographic exchange in exchange for the tokens that can be sold, used for future products or services purchase or profit. Constantly evolving technologies, the growing use of cryptocurrencies and the changing needs of market participants have led to the emergence of this innovative investment and financing instrument which is rapidly gaining ground in an extremely short period of time. Despite the fact that the various advantages of the ICO causes its attractiveness, increasing popularity and relevance in the modern market, investors or companies are also exposed to a number of

\footnotetext{
* This research was supported by Kaunas University of Technology, School of Economics and Business, Lithuania
} 


\section{ENTREPRENEURSHIP AND SUSTAINABILITY ISSUES}

ISSN 2345-0282 (online) http://jssidoi.org/jesi/

2020 Volume 7 Number 3 (March)

http://doi.org/10.9770/jesi.2020.7.3(3)

risks. Obviously, the market of the ICO is extremely new, constantly changing and has the potential to further expand in the future, but it has so far been poorly explored, challenging both investors and businesses to choose the most appropriate and successful investment or financing strategy. Considering this, various scientists has started to analyze the concept, regulation of the ICO (Kaal, 2018; Barsan, 2017), comparison with other financing methods (Ofir and Sadeh, 2018; Hu, Parlour, and Rajan, 2018) various success factors (Ante et al., 2018; Momtaz, 2018; Lee, Li, and Shin, 2018; Burns and Moro, 2018). Scientists often point out that this area is still rather vague, poorly researched, risky, lacking in generalizing and unanimous conclusions, methodological guidelines for investors and companies seeking to successfully use ICO for investment or funding, taking into account the determinants that have the greatest impact on their success.

Purpose of the article. Following the analysis of the scientific literature, make recommendations to investors and companies on the factors that influence the success of the initial coin offerings the most in order to successfully invest or use it for financing.

Methodology / methods. Analysis of scientific literature, comparison, aggregation, grouping, collection of statistical data, analysis, systematization.

Findings. Before ICO emerged, companies used traditional financing methods such as bank loans, shares, venture capital, crowdfunding ant others to attract funding. It is clear that the growing popularity of the ICO is due to a number of its advantages, such as the high level of investment return offered, high liquidity, fast financing, cost minimization and high availability, which are increasingly encouraging innovative investors and businesses to forget traditional financing methods. Nevertheless, the ICO market is young, indefinite, constantly growing and changing, faced with significant risks of poor regulation and investor protection, information asymmetry, potential fraud and lack of methodological guidance. Given the strengths and risks of ICO, the popularity of its application is determined by success factors such as the amount of funding attracted, listing, return on investment, market capitalization and duration of the ICO.

Conclusions. There are a lot of strengths and weaknesses of the ICO mentioned in the scientific literature. Although ICO offers high liquidity, return on investment, availability, fast capital raising process, minimization of capital raising costs, those benefits are often available only when companies or investors agree to take considerable risks, caused by the information asymmetry, lack of investor protection, proper regulation and methodical guidance both for investors and entrepreneurs. The analysis of the ICO success indicators suggests that the most commonly used indicator for the success of companies or entrepreneurs is the amount of funding attracted by the ICO. In terms of indicators defining the success of investors, ICO's return on investment is most often used. Also, widely used ICO success measures are the listing of coins on a variety of virtual platforms, market capitalization of the coins and the duration of the ICO.

\section{Reasons for the growing popularity of ICO}

The Initial Coin Offering (ICO), which was first held in 2013, as Amsden and Schweizer (2018) claim, due to the potential of rapidly evolving technologies and the growing popularity of crypto currencies, has created new business models and, at the same time, the need to raise capital and accelerate business growth. According to Boreiko and Vidusso (2018), rapid technological change, the beginning of financial technologies, excessive regulation of the financial sector and the inability to adapt to the ever-changing needs of small debtors have led to the emergence of previously unheard alternative financing methods. According to Huang, Meoli, and Vismara (2019), along with the continuing increase in popularity of crypto currencies, a new opportunity has emerged for businesses to use them as a way to raise funds and finance new projects through ICO. As pointed out by Amsden and Schweizer (2018), a mechanism was proposed to raise funds without using traditional financing methods such as venture capital, crowdfunding or initial public offering of shares, but using blockchain technology instead to 


\section{ENTREPRENEURSHIP AND SUSTAINABILITY ISSUES}

ISSN 2345-0282 (online) http://jssidoi.org/jesi/

2020 Volume 7 Number 3 (March)

http://doi.org/10.9770/jesi.2020.7.3(3)

sell virtual tokens. Given the novelty of this concept and the fact that the biggest breakthrough of ICO occurred in 2017, when the ICO number increased significantly and, according to Boreiko and Sahdev (2018), the amount of capital attracted through the ICO outperformed traditional venture capital funds, most of the scientific literature on this topic is found from 2017-2018. Most often the scientific literature analyzes the concept of ICO while comparing it with other ways of funding, ICO regulation, success factors, which in general highlight the main advantages of ICO, increasing their attractiveness and popularity, as well as risks that cause market volatility and harder decision making.

Until the emergence of ICO, in order to attract financing companies used traditional financing methods, such as bank loans, stocks, venture capital, crowdfunding, etc. Obviously, the ICO has a lot of similarities to other ways of raising capital. As Barsan (2017) points out, ICOs are similar to Initial Public Offering (IPO), where companies sell part of their capital on the stock market and crowdfunding, when funding is drawn from a heterogeneous group of investors on virtual platforms. With the growing popularity of ICO, as Amsden and Schweizer (2018) point out, entrepreneurs quickly realized that the ICO could be structured to resemble other forms of financing that are already developed, such as shares, bonds, crowdfunding, venture capital, private equity funds, hedge funds, etc. According to Ofir and Sadeh (2018), the rapidly growing popularity of ICO was accelerated by their use as a protection against volatile local currencies and geopolitical risks, distrust of the traditional banking sector after 2008 global financial crisis and increased media attention. The ever-growing popularity of ICO shows that ICO offers a number of advantages to both investors and businesses or entrepreneurs that motivates them to choose exactly this type of financing or investment (see Figure 1).

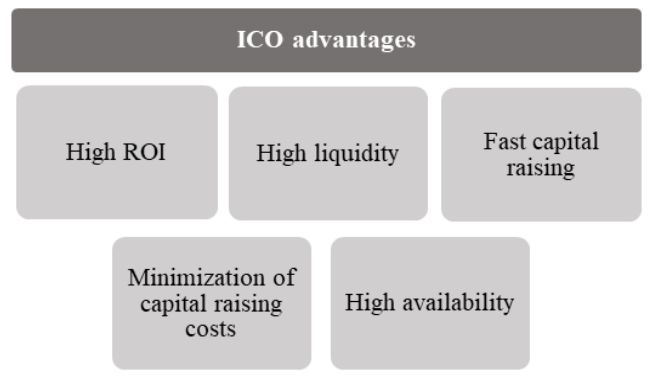

Fig. 1. The advantages of ICO that are usually analysed in scientific literature.

In particular, in the case of investors, Fisch, Masiak, Vismara and Block (2018) study of the motives to invest in ICO has shown that some of the most important for the investors are ideological, technological and investment motives. Although the authors emphasized the importance of ideological motives, which illustrates the uniqueness of ICOs in the context of funding for entrepreneurship, because such motives are not usually characteristic of more traditional forms of financing. Nonetheless, investor decisions are also heavily influenced by financial motives, one of which is the extremely high return on investors offered by ICO. After their study, Benedetti and Kostovetsky (2018) noticed a significant underpricing of the ICO and an average of 179 percent seeking first day return. The authors also found that after the start of trading, the price of coins continues to rise, generating an average of 48 percent return on the first 30 trading days. Such high returns Benedetti and Kostovetsky (2018) explain as a compensation to investors for investing in high-risk, often unverified and non-revenue generating platforms through unregulated trading, lack of competency in determining the market demand of the coins, a higher uncertainty of the value of the start-up platform that is often only in the idea stage and the hurry to sell the coins faster so that the platform, once funded, could operate. This shows that for investors driven by financial motives, ICO can be an attractive investment alternative as it can offer an extremely high return on investment if successful. 


\section{ENTREPRENEURSHIP AND SUSTAINABILITY ISSUES}

ISSN 2345-0282 (online) http://jssidoi.org/jesi/

2020 Volume 7 Number 3 (March)

http://doi.org/10.9770/jesi.2020.7.3(3)

High liquidity also increases the popularity and attractiveness of ICOs for investors. Adhami, Giudici, and Martinazzi (2018) argue that the coin mechanism allows investors to create a secondary market for their investments, thus increasing their liquidity. Benedetti and Kostovetsky (2018) point out that shortly after ICOs, coins are listed on one or more virtual platforms, providing liquidity to investors and enabling the sale of purchased coins in the secondary market. Comparing ICOs with other investment alternatives, Kaal (2018) states that ICO provides investors with the greatest liquidity faster than any other form of capital formation. ICO's liquidity is also highlighted by Hu, Parlor and Rajan (2018), arguing that coins can sometimes be sold on the secondary market even before the ICO is finished, while risk capital investments are less liquid and often can be retained for several years before their potential sale. According to Momtaz (2018), most coins are listed on a virtual platform within three months after the end of the ICO, and emphasizes that neither crowdfunding nor risk capitalists can provide a similar level of liquidity. All this shows that for investors seeking high liquidity and the ability to quickly recover the invested money and additional return, the ICO is a fairly attractive investment solution, often providing much higher liquidity than any other investment alternative.

In terms of start-ups or other companies seeking to attract funding through ICOs, their attractiveness is enhanced by the potential for fast funding. According to Kaal (2018), ICO allows for fast funding, avoiding the often long, complicated financing process when choosing traditional financing methods. The speed of ICO funding is highlighted by De Jong, Roosenboom and Van der Kolk (2018), pointing out that some blockchain start-ups were able to raise capital through the ICO at record speed and gives an example of the company called Gnosis, which got 12 million dollars of financing in less than 10 minutes. Barsan (2017) refers to Bancor Protocol, which attracted more than 150 million dollars within 3 hours in 2017. De Jong et al. (2018) points out that some startups in the blockchain were able to raise funds at record speeds, mainly due to investors' fear of missing out. According to Amsden and Schweizer (2018), ICO characteristics such as their virtuality, globalization and poor regulation help attract more investors, which also contributes to the speed of funding.

Another important factor in increasing the attractiveness of ICOs as a financing method is the minimization of funding costs, which happens largely due to the fact that ICOs usually do not require any financial intermediaries. As one of the most important advantages of ICO, Kaal (2018) identifies their cost efficiency, which compensates for market complexity and unpredictability. According to Boreiko and Sahdev (2018), the smooth functioning of modern economy is not imaginable without financial intermediaries, such as banks or other companies providing financial services, which reduce the asymmetry of information, but on the other hand can also often operate more on their own interests. Choosing another method of financing, for example IPO, it is usually not possible to avoid the cost of financial intermediaries, but according to Boreiko and Sahdev (2018), companies seeking to raise capital through the innovative blockchain based technologies do not need high marketing and advertising or intermediary costs which helps to reduce the cost of raising capital and thus increase the attractiveness of this method of financing.

In literature, one of the most important advantages of ICO for both investors and businesses is also often mentioned the greater availability compared to other forms of financing or investment, which is largely due to the still rather poor regulation. Comparing ICOs with other financing or investment alternatives, Rhue (2018) states that there is a wide range of legal and financial requirements to raise funds using the IPO, while the ICO process is relatively easier. As for the availability of ICO, An, Duan, Hou, and Xu (2019) point out that due to their virtuality, low level of regulation, ICO allows investing and using ICOs to finance or invest for a wider range of investors and companies for which traditional investment or financing methods could not be available. Although ICO provides opportunities to attract funding for companies or invest for investors that do not meet often fairly high requirements when choosing other alternatives, Fisch (2018) point out that due to their high-tech nature, ICOs are generally only available to companies using blockchain technologies. However, as the use of the blockchain becomes more and more popular, ICO is becoming more accessible and used by a wider range of companies. 


\section{ENTREPRENEURSHIP AND SUSTAINABILITY ISSUES}

ISSN 2345-0282 (online) http://jssidoi.org/jesi/

2020 Volume 7 Number 3 (March)

http://doi.org/10.9770/jesi.2020.7.3(3)

The availability and popularity of ICOs is also increased by the globalization of financing. According to Boreiko and Sahdev (2018), ICO virtualization makes it possible for anyone, anywhere in the world, to invest in a company that is also established or operating in any country. Companies can leverage social networks and other virtual communication channels to attract funds from abroad that are not limited by local financial system. According to Boreiko and Sahdev (2018), traditional sources of funding, such as bonds, stocks, venture capital funds or bank loans are localized in a specific geographical area and defined in its legislation. Such a global nature of ICO allows to attract more international investors and expand their investment opportunities. As Chen (2018) point out, that is how ICO is changing fundraising, by democratizing the access to financial capital and allowing to finance projects much faster, easier and more efficiently.

It is clear that the rapidly growing popularity of ICOs has a number of reasons that increase their attractiveness for both investors and companies seeking financing. This explains the ever-increasing number of ICOs and the likely future growth. Nonetheless, the noticeable benefits of ICOs are often available only when companies or investors agree to take some considerable risks.

\section{ICO limitations and risks}

In literature ICO is often mentioned as new, volatile, high-interest, but still poorly researched innovative financing method. As Amsden and Schweizer (2018) claim, ICO, as a method of raising capital for blockchain based companies, is a new phenomenon and little is known about the decision-making process of ICO investors. They are also supported by De Jong et al. (2018) pointing out that despite the growing popularity of the ICO, the number of successful ICOs began to decline, and regulators drew attention to the risks of largely unregulated ICOs, that are often mentioned in the literature (see Figure 2).

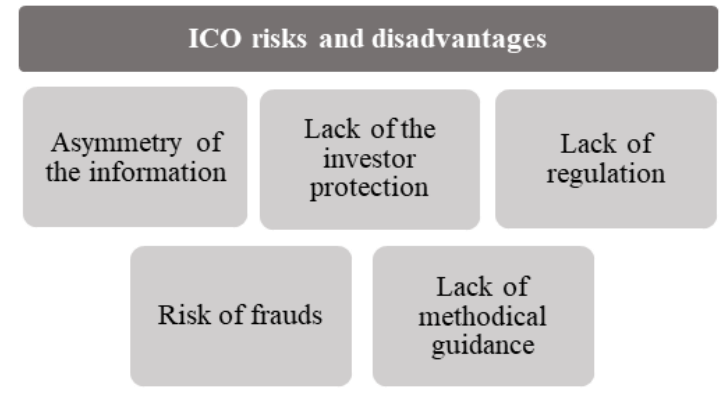

Fig. 2. The most often analysed risks and disadvantages of ICO in the scientific literature.

One of the most important factors that increases the market risk of ICOs and makes decision-making more difficult is the asymmetry of information and the amount of information disclosed that is often too low. First of all, one of the already mentioned advantages of the ICO, which is non-use of intermediary services may make it difficult to obtain proper information about the ICO. According to Li and Shin (2018), in order to overcome the asymmetry of information while using IPO, financial intermediaries are conducting an inspection and assessing the value and the risk of the business, the price of the shares being sold, while intermediary services are not used through the ICO.

Considering the immediate nature of ICO transactions and the resulting problems, Boreiko and Sahdev (2018) said that a significant number of virtual platforms have started providing ICO listing, analysis and rating services for investors to meet their information needs, which are usually met by financial intermediaries while using traditional financing methods. At first glance, it would appear that the information provided on such platforms 


\section{ENTREPRENEURSHIP AND SUSTAINABILITY ISSUES}

ISSN 2345-0282 (online) http://jssidoi.org/jesi/

2020 Volume 7 Number 3 (March)

http://doi.org/10.9770/jesi.2020.7.3(3)

would allow the fastest and most reliable assessment of the ICO's prospects. De Jong et al. (2018) research of the ICO expert ratings presented in various ICO platforms showed that expert ratings are a valuable tool to overcome the information asymmetry associated with ICO. On the other hand, a research of ICO ratings from various sources of information conducted by Rhue (2018) showed that it is quite difficult for investors to get reliable guidance on ICOs. Boreik and Sahdev (2018) research of the ICO ratings and listing platforms showed, that the information on various ICO platforms do not always correlate, sometimes they use different data for rating which is often undermining their credibility. Because of that it is difficult for investors to get objective information about the ICOs of interest and make the right investment decisions. The assessment of information, market tracking and analysis is also hampered by the fact that, as Fisch (2018) claims, there is no single ICO platform or database, nor is ICO registration required.

The lack of ICO regulation and the lack of appropriate disclosure requirements also contribute to information asymmetry. Amsden and Schweizer (2018) say that there is no uniform format for white paper, often comparable to the IPO-provided prospectus, rules regarding the information contained therein, which also increases the asymmetry of information, complicates the comparison of different ICOs and decision making. Companies, considering that disclosure of ICO information is not regulated, often provide not enough information for investors. Kaal (2018) argues that the lack of mandatory disclosure requirements results in irregular and inadequate disclosure of information and reduces the transparency of the ICO market. According to Blaseg (2018), the regulations of the information disclosure would not be necessary if companies voluntarily disclosed relevant information enabling informed decisions to be made and its value would be recognized by investors. Amsden and Schweizer (2018) also point out that, in the case of ICO, the amount and methods of disclosures depend on the ICO implementing company, so investors need to assess the information they receive independently, which, according to Amsden and Schweizer (2018), can often become quite complicated with regard to the fact that a large part of ICO's investors are small, often without sufficient financial and investment knowledge.

The lack of investor protection is also often mentioned as one of the most important ICO risks. As already mentioned above, ICO provides a great return for investors, but this is only possible with a significant risk associated with the ICO. According to Chen (2018), ICOs are usually implemented at the earliest stages of project life, when their future prospects are not yet clear and predictable, so investors may lose all their invested money in the event of a project failure. Kaal (2018) points out that ICO investors, unlike shareholders, do not have any control over the company they invested in and usually invest in the idea of a future product or service and one of the few ways to protect their investments is to sell the coins after the ICO ends.

According to Ante, Sandner, Fiedler, Tumasjan and Welpe (2018), the ICO market is still characterized as having very high returns for investors, but lacking proper regulation. The lack of regulation has already been mentioned as one of the advantages of the ICO, increasing their availability, but it also poses considerable risks and uncertainties in the ICO market. The lack of clear regulation and the associated risks have brought regulators' attention to ICO worldwide. According to Boreiko and Sahdev (2018), ICO has the potential to quickly and unpredictably change the traditional financial and banking industry, which has led many national regulators to consider it suspicious and fearsome. A study conducted by Kaal (2018) on ICO regulation in various countries showed that in 25 leading countries by ICO market capitalization a favourable attitude prevails over ICOs and most countries such as Switzerland, Singapore or Japan allow ICOs and crypto currencies and use existing laws to regulate it or just wait how other countries will react to this crypto evolution. However, according to Kaal (2018), there are countries that banns ICOs and crypto currencies, such as China and South Korea, while others only warn of the risks associated with ICOs, setting limits that cannot be overstated and advise not to invest in ICO (for example USA). Huang et al. (2019) found that most ICOs are implemented in countries that regulate ICOs and have established favorable ICO regulation, have more developed financial markets, digital technologies and availability of investment-based crowdfunding platforms. 


\section{ENTREPRENEURSHIP AND SUSTAINABILITY ISSUES}

ISSN 2345-0282 (online) http://jssidoi.org/jesi/

2020 Volume 7 Number 3 (March)

http://doi.org/10.9770/jesi.2020.7.3(3)

Obviously, as Barsan (2017) argues, the positions of regulators from different parts of the world in terms of ICO are different and it is not clear if decisions taken in one jurisdiction could be successfully adapted and transferred to another one. Such volatility can also cause some difficulties in applying the ICO. According to Wisniewska (2018), one of the most challenging parts of the ICO application is legal barriers, because the ICO market is virtual and global, and depending on the country, ICOs can be banned, partially or completely regulated.

Despite the ever-growing need for regulation, Barsan (2017) points out that over-regulation could possibly reduce the popularity of ICOs, making it difficult to implement an ICO that meets potentially conflicting rules. He is supported by Fisch et al. (2018) pointing out that overly cohesive ICO regulation can reduce their innovative potential and regulators should pay attention to the different motives to invest in ICOs and try to reduce the investment risk of ICOs without compromising their technological side.

The uncertainty of the ICO market is underlined by Albrecht, Lutz and Naumann (2019) that points out that legislators are concerned about the possibility of the financial fraud while using ICO. Wisniewska (2018) points out that ICOs should be treated cautiously due to the high risk of fraud. Those authors are also supported by Boreiko and Sahdev (2018) stating that one of the biggest problems of ICO is the risk of fraud, as the whole process is carried out virtually and mostly anonymously, enabling both investors and project teams not to reveal their identity, which makes it particularly difficult to track down where the misappropriated funds went in case of the fraud. ICO can be used for frauds in a variety of ways. Barsan (2017) refers to cyber security, cyber attacks and possible fraud such as the use of the Ponzi scheme. Benedetti and Kostovetsky (2018) claim that the anonymity of crypto currencies accounts, irrevocability of transactions, and poor regulation of ICOs create conditions for fraud and theft, for example hacking into a legitimate ICO website or social networking account and replacing instructions so that investors send money to the scammers instead of the legitimate coin sellers. According to the authors, the ICO organizers themselves may be scammers using various fraud schemes, ultimately neglecting a project that has received funds and keeping most of the funds raised for themselves.

According to Wisniewska (2018), the aforementioned ICO risks, poor presentation of the project and the lack of information, resulting in increased investor distrust may lead to insufficient demand for coins, which would complicate the achievement of the set financing targets and ICO results. Various factors that influence the results and success of ICO are widely explored in scientific literature. Researchers often take into account and compare the results with research on the success factors of crowdfunding (Ahlers, Cumming, Günther and Schweizer, 2015). Scientists also analyse the impact of information disclosure (Blaseg, 2018), company technological capabilities (Fisch, 2018), human capital (An et al. 2019), social network (Albrecht et al. 2019), expert ratings (Boreiko and Vidusso, 2018, Rhue, 2018), other factors (Ante et al., 2018, Momtaz, 2018, Lee, Li and Shin, 2018, Burns and Moro, 2018, Amsden and Schweizer, 2018, Fenu, Marchesi, Marchesi and Tonelli, 2018, De Jong et al. 2018, Adhami et al., 2018). Nevertheless, it is often stated that there is a lack of generalized conclusions on ICO success factors and more specific methodological guidelines for investors or companies, which also increases the uncertainty and risk of the ICO market. Adhami et al. (2018) states that the understanding of the success factors of ICO campaigns is crucial for the structuring of future coin sales, as it signals the key factors that influence the success of a project, which is what the potential investors seek. According to Rhue (2018), there are limited practical recommendations for companies seeking to raise funds through the ICO on what factors or decisions may determine the success of the project. They are also supported by Fisch (2018) stating that despite the great interest of investors, companies and government institutions in the ICO, it is still little known about the dynamics of ICO as a funding mechanism and it is unclear what factors affect the amount of capital attracted by the ICO.

It is evident that the growing popularity of ICOs is due to a number of its advantages, such as the high level of return, high liquidity, speed of fundraising and cost minimization, high availability, that increasingly encourages innovative investors and companies to forget traditional ways of financing. Nevertheless, the ICO market is 


\section{ENTREPRENEURSHIP AND SUSTAINABILITY ISSUES}

ISSN 2345-0282 (online) http://jssidoi.org/jesi/

2020 Volume 7 Number 3 (March)

http://doi.org/10.9770/jesi.2020.7.3(3)

young, indefinite, constantly growing and changing, faced with significant risks of poor regulation and investor protection, asymmetry of information, and possible fraud. According to Chen (2018), the ICO, which is still underdeveloped and controversial, will continue to develop in the future, which will allow it to become increasingly important in the financing of innovation and entrepreneurship. Due to the identified shortcomings of ICOs, in particular asymmetry of information and insufficient regulation, it is difficult for market participants to assess the ICO fairly and relatively easily and to make appropriate investment or financing decisions that could minimize the risks associated with ICOs as much as possible. The ICO, taking into account all its advantages, is becoming more and more frequent, but so far it has not been thoroughly researched and it is not clear how its advantages, risks and other factors affect its success. Investigating ICO success factors can benefit both potential investors looking for ICOs to invest successfully and understand how to identify project-related factors and their impact on its success, as well as start-ups and other companies seeking to use ICO successfully and attract funds in such a volatile market. In most of the research articles analyzed, the need for further ICO success factors research is indicated and considering the novelty, volatility, emerging risks, growing popularity of the ICO market and the lack of research in the scientific literature, concrete conclusions and methodological recommendations, it is important to investigate the factors that influence the success of the ICO the most.

\section{Evaluation of ICO success}

There are a lot of different measures of success used in the scientific literature, while analysing the ICO success factors and their impact on ICO results (see Figure 3). Many scientists use more than one ICO success measure in their research and investigate the influence of the various factors they have chosen. The first ICO studies were based on the results of previous research on crowdfunding, IPO or other funding methods that are often compared to ICOs. Nonetheless, not all the measures of success used to assess other funding methods can be properly adapted to the ICO. According to Amsden and Schweizer (2018), the implementation of ICO requires the development of a new revolutionary technology, the decentralization of existing technologies, most of its implementing companies are only in an idea or at a very early stage of life, so there is a significant likelihood of significant changes in those companies concept from the beginning of the ICO to the final product development. In view of the challenges it poses, comparing product yields with the set goals, delivering on time, achieving the set maximum amount of attracted funding, unlike in the case of crowdfunding, are not proper measures of ICO success. Ahlers et al. (2015), while investigating the success factors of crowdfunding, as one of the measures of success use the number of investors, which in case of ICO would not normally be possible due to the potential anonymity of the investors (see Figure 3)..

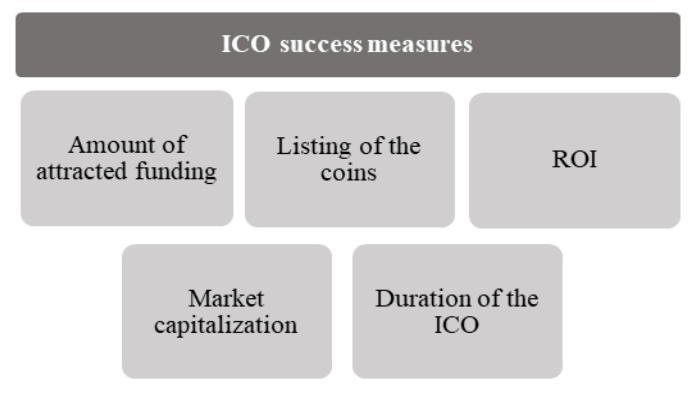

Fig. 3. ICO success measures that are most often analysed in the scientific literature

One of the most widely used ICO success measures in the scientific literature is its attracted amount of funding. According to Boreiko and Vidusso (2018), in view of the complexity and riskiness of the blockchain based startup, it would often not be possible to successfully implement the project without the availability of a certain 


\section{ENTREPRENEURSHIP AND SUSTAINABILITY ISSUES}

ISSN 2345-0282 (online) http://jssidoi.org/jesi/

2020 Volume 7 Number 3 (March)

http://doi.org/10.9770/jesi.2020.7.3(3)

budget. Rhue (2018), Ante et al. (2018), Blaseg (2018), Boreiko and Midlands (2018), Fisch (2018), Lee et al. (2018), Momtaz (2018), Burns and Moro (2018), Albrecht et al. (2019), An et al. (2019), Amsden and Schweizer (2018), De Jong et al. (2018) measure the success of the ICO by the amount of funds attracted and identifies it as a measure of success for the entrepreneurs. Its popularity is also noted by An et al. (2019) pointing out that this ICO success measure is widely used in scientific literature and is the most accurate measure of company access to external funding through the ICO. Fisch (2018) also agrees and points out that the amount of funds raised is the most commonly used measure of success in the research of the funding of entrepreneurship. According to Boreiko and Vidusso (2018), this is a fairly intuitive measure of investor interest and belief in the project. The success is measured by the amount of money attracted not only in the case of ICO. Ahlers et al. (2015) also use this measure of success in researching the success factors of crowdfunding, which is often compared to ICO.

Also, the authors often use other ICO success measures related to the amount of funding attracted in their research. Quite often, the amount of funding attracted by the ICO is compared with the established minimum amount of funding, which is called a softcap. Adhami et al. (2018), De Jong et al. (2018) and Lee et al. (2018) agrees, that the ICO can be called successful if it has reached the set minimum funding target. In most cases, when the minimum funding threshold is not reached, the company does not receive any funding because, as Adhami et al. (2018) said, in that case investors usually retrieve their invested funds. Adhami et al. (2018) states that ICOs may be unsuccessful and attract a very small amount or no funding due to low demand for coins offered, security flaws, cyber attacks, potential fraud, etc. According to Boreiko and Vidusso (2018), this ICO success measure is particularly appropriate given that once the minimum funding amount is reached, the entrepreneurs have sufficient funds and can start implementing a new project. On the other hand, the use of this definition of success may not always be reasonable, as, according to Boreiko and Vidusso (2018), this measure does not take into account the amount of funds that is missing to reach the target amount and there may be such ICOs for which the minimum funding amount is not even established. For this reason, Fenu et al. (2018) decided to extend this definition of ICO success by arguing that there is often a lack of data on the set minimum amount of funding attracted by the ICO and that sometimes the ICO provides provisions to implement the ICO, even if the minimum funding amount is not reached. Based on this, Fenu et al. (2018) argues, that a successful ICO is the one attracting more than 200000 dollars. In the absence of a minimum threshold for attracted funding, Lee et al. (2018) says that a successful ICO is the one that has succeeded in attracting more than 500000 dollars.

Some scientists use other various measures of the amount of funding attracted. De Jong et al. (2018) and Lee et al. (2018) says that the success of the ICO is also measured by the percentage of funds raised of the maximum amount of the funding set, which is called a hardcap. Blaseg (2018) argues that a successful ICO is able to attract any amount of funding.

Another common definition of ICO's success in scientific literature is the listing of its coins on various virtual platforms. De Jong et al. (2018), Blaseg (2018) points out that successful ICOs are those whose coins are traded on at least one of virtual exchange platforms. This definition of the success of ICO is most important for Amsden and Schweizer (2018) that states that listing is equally important both for investors by providing them with liquidity, as well as for entrepreneurs or companies by providing additional capital by offering unsold coins in the future. The importance of listing Amsden and Schweizer (2018) also highlights by the fact that it is often needed for successful project functioning, when the platform or product is only available to the coin owners after the end of the ICO. In that case the unlisted coins would not be available to potential users and the project would fail, despite the amount of funding attracted. Clearly, the success of crypto currencies and ICOs depends on their usability, which is why, as Momtaz (2018) claims, they are usually being listed on as many virtual exchanges as possible. Listing can also be an important signal to investors about the quality of the ICO and the company or the project itself, as Amsden and Schweizer (2018) argue that the virtual exchange platforms protect their reputation and carefully check listed ICOs to detect fraudulent or questionable value projects. On the other hand, a number of shortcomings in the use of this definition of success are highlighted. According to Blaseg (2018), measuring 


\section{ENTREPRENEURSHIP AND SUSTAINABILITY ISSUES}

ISSN 2345-0282 (online) http://jssidoi.org/jesi/

2020 Volume 7 Number 3 (March)

http://doi.org/10.9770/jesi.2020.7.3(3)

ICO's success by listing only evaluates early-stage performance and does not depend on the success of ICO funding, as even not funded projects coins can be listed.

Also, ICO's success is quite often measured by the return on investment. One of the main motives for investing in ICOs is the high return they often offer to investors, so, according to Burns and Moro (2018) and Rhue (2018) ICO success is measured by Return on Investment (ROI) and named as one of the most important measures of investor success. Short-term return rates are also used. Burns and Moro (2018) and Momtaz (2018) use the firstday return to measure the success of the ICO, and Momtaz (2018) argues that successful are those ICOs whose first-day returns are positive.

The success of the ICO is also defined as the market capitalization of its coins (Rhue (2018)), when higher capitalization means a more successful ICO. As a success measure is also used a change in market capitalization. Fenu et al. (2018) unsuccessful consider those ICOs whose market capitalization has declined by more than 75 percent within six months after their listing start.

One more measure of the success of the ICO, which is quite common in scientific literature, is its duration. An et al. (2019) measure ICO success by its length of days, showing how quickly a young company can attract funding and is labeled as a reflection of the quality of the company and the ICO itself. The shorter duration is considered to be the attribute of success of the ICO, and Lee et al. (2018) says that a highly successful ICO usually ends when their hardcap is reached and a longer funding campaign distracts the management who needs to focus on product development. This measure of success is also used by Ahlers et al. (2015) while examining the success of crowdfunding as it is particularly important for young and fast-growing innovative companies, seeking to get funding as soon as possible. Other alternative duration indicators are also used. Momtaz (2018) measures the success of the ICO by the time to market which assesses the number of days since the project was created until the start of the ICO.

Finally, various indicators are used to define the success of the ICO after its completion. De Jong et al. (2018) argues that a successful ICO after its completion is the one that still has active project's web site, its project team post at least one tweet on Twitter, use the Github repository six months after the end of the ICO and measures ICO success by the number of tweets a week from the start of ICO to six months after its end. In this case, the activity on social networks is used to measure the success of the ICO, which usually only happens if the company successfully implements the ICO and attracts a sufficient amount of funding to start and continue its activities.

Thus, it is clear that in the scientific literature the success of the ICO is defined by a number of different indicators and there is no consensus on which one is most appropriate. Nevertheless, it can be concluded that the most commonly used indicator defining the success of the ICO important mostly for entrepreneurs is the amount of funding attracted by the ICO. In terms of indicators defining the success of investors, ICO's return on investment is most often used. Also, the widely used ICO success measure is the listing of the coins on a variety of virtual platforms, which is important and defines the success of both investors and companies or entrepreneurs.

\section{Conclusions}

Rapid changes in financial technology caused by the emergence of the blockchain, inflexibility of the financial sector, excessive regulation and inability to adapt to the ever-changing needs of small debtors have led to the emergence of previously unheard of, alternative, innovative, digital funding mechanisms. Although there are a lot of strengths and weaknesses of the ICO mentioned in the scientific literature, the analysis of the ICO success indicators suggests that the most commonly used indicator for the success of companies or entrepreneurs is the amount of funding attracted by the ICO. In terms of indicators defining the success of investors, ICO's return on investment is most often used. Also, widely used ICO success measure is the listing of coins on a variety of virtual platforms, which is important and defines the success of both investors and companies or entrepreneurs. 


\section{ENTREPRENEURSHIP AND SUSTAINABILITY ISSUES}

ISSN 2345-0282 (online) http://jssidoi.org/jesi/

2020 Volume 7 Number 3 (March)

http://doi.org/10.9770/jesi.2020.7.3(3)

\section{References}

Adhami, S., Giudici, G., Martinazzi, S. 2018. Why Do Businesses Go Crypto? An Empirical Analysis of Initial Coin Offerings. Journal of Economics and Business. 100: 64-75. https://doi.org/10.1016/j.jeconbus.2018.04.001

Ahlers, G. K. C., Cumming, D., Günther, C., Schweizer, D. 2015. Signaling in Equity Crowdfunding. Entrepreneurship Theory and Practice. 39(4): 955-980. https://doi.org/10.1111/etap.12157

Albrecht, S., Lutz, B., Naumann, D. 2019. How Sentiment Impacts the Success of Blockchain Startups - An Analysis of Social Media Data and Initial Coin Offerings. Proceedings of the 52nd Hawaii International Conference on System Sciences. 4545-4554. https://scholarspace.manoa.hawaii.edu/bitstream/10125/59892/0452.pdf

Amsden, R., Schweizer, D. 2018. Are Blockchain Crowdsales the New 'Gold Rush'? Success Determinants of Initial Coin Offerings. SSRN. http://dx.doi.org/10.2139/ssrn.3163849

An, J., Duan, T., Hou, W., Xu, X. 2019. Initial Coin Offerings and Entrepreneurial Finance: The Role of Founders' Characteristics. The Journal of Alternative Investments 21(4): 26-40. https://doi.org/10.3905/jai.2019.1.068

Ante, L., Sandner, P., Fiedler, I., Tumasjan, A., Welpe, I. 2018. Blockchain-Based ICOs: Pure Hype or the Dawn of a New Era of Startup Financing? Journal of Risk and Financial Management 11(4): 1-19. https://doi.org/10.3390/jrfm11040080

Barsan, I. M. 2017. Legal Challenges of Initial Coin Offerings (ICO). Revue Trimestrielle de Droit Financier (RTDF) 3: 54-65. https://ssrn.com/abstract $=3064397$

Benedetti, H. E., Kostovetsky, L. 2018. Digital Tulips? Returns to Investors in Initial Coin Offerings. SSRN. http://dx.doi.org/10.2139/ssrn.3182169

Blaseg, D. 2018. Dynamics of Voluntary Disclosure in the Unregulated Market for Initial Coin Offerings. SSRN. http://dx.doi.org/10.2139/ssrn.3207641

Boreiko, D., Sahdev, N. K. 2018. To ICO or not to ICO - Empirical Analysis of Initial Coin Offerings and Token Sales. SSRN. http://dx.doi.org/10.2139/ssrn.3209180

Boreiko, D., Vidusso, G. 2019. New Blockchain Intermediaries: Do ICO Rating Websites Do Their Job Well? The Journal of Alternative Investments 21(4): 67-79. https://doi.org/10.3905/jai.2019.21.4.067

Burns, L., Moro, A. 2018. What Makes an ICO Successful? An Investigation of the Role of ICO Characteristics, Team Quality and Market Sentiment. SSRN. http://dx.doi.org/10.2139/ssrn.3256512

Chen, Y. 2018. Blockchain tokens and the potential democratization of entrepreneurship and innovation. Business Horizons 61(4): 567575. https://doi.org/10.1016/j.bushor.2018.03.006

De Jong, A., Roosenboom, P., van der Kolk, T. 2018. What Determines Success in Initial Coin Offerings? SSRN. http://dx.doi.org/10.2139/ssrn.3250035

Fenu, G., Marchesi, L., Marchesi, M., Tonelli, R. 2018. The ICO phenomenon and its relationships with ethereum smart contract environment. 2018 International Workshop on Blockchain Oriented Software Engineering (IWBOSE). $26-32$. http://dx.doi.org/10.1109/IWBOSE.2018.8327568

Fisch, C. 2018. Initial Coin Offerings (ICOs) to Finance New Ventures. Journal of Business Venturing 34(1): 1-22. https://doi.org/10.1016/j.jbusvent.2018.09.007

Fisch, C., Masiak, C., Vismara, S., Block, J. H. 2018. Motives to Invest in Initial Coin Offerings (ICOs). SSRN. http://dx.doi.org/10.2139/ssrn.3287046

Hu, A., Parlour, C. A., Rajan, U. 2018. Cryptocurrencies: Stylized Facts on a New Investible Instrument. SSRN. http://dx.doi.org/10.2139/ssrn.3182113 


\section{ENTREPRENEURSHIP AND SUSTAINABILITY ISSUES}

ISSN 2345-0282 (online) http://jssidoi.org/jesi/

2020 Volume 7 Number 3 (March)

http://doi.org/10.9770/jesi.2020.7.3(3)

Huang, W., Meoli, M., Vismara, S. 2019. The Geography of Initial Coin Offerings. Small Business Economics (Online First). https://doi.org/10.1007/s11187-019-00135-y

Kaal, W. A. 2018. Initial Coin Offerings: The Top 25 Jurisdictions and Their Comparative Regulatory Responses. Stanford Journal of Blockchain Law \& Policy 1(1): http://dx.doi.org/10.2139/ssrn.3117224

Lee, J., Li, T., Shin, D. 2018. The Wisdom of Crowds in FinTech: Evidence from Initial Coin Offerings. SSRN. http://dx.doi.org/10.2139/ssrn.3195877

Momtaz, P. P. 2018. Initial Coin Offerings. SSRN. http://dx.doi.org/10.2139/ssrn.3166709

Ofir, M.; Sadeh, I. 2018. ICO vs IPO: Empirical Findings, Market Frictions and the Appropriate Regulatory Framework. International Journal of Organizational Leadership 7: 120-128. http://dx.doi.org/10.2139/ssrn.3338067

Rhue, L. 2018. Trust is All You Need: An Empirical Exploration of Initial Coin Offerings (ICOs) and ICO Reputation Scores. SSRN. http://dx.doi.org/10.2139/ssrn.3179723

Wisniewska, A. 2018. The Initial Coin Offering - Challenges and Opportunities, Copernican Journal of Finance \& Accounting 7(2): 99110. http://dx.doi.org/10.12775/CJFA.2018.011

\section{Aknowledgements}

This research was supported by Kaunas University of Technology, School of Economics and Business, Lithuania

Alfreda ŠAPKAUSKIENE Associate Professor, PhD of Social Sciences field, Management and Administration, Researcher of Sustainable Economy Research Group, School of Economics and Business, Kaunas University of Technology and Assoc. Professor, Department of Finance, Faculty of Economics and Business Administration, Vilnius University. Research interests: Finance, FinTech, Blockchain, Cryptoccurency, ICO, IFRS, Personal Finance, Behavioral Finance.

ORCID: 0000-0002-0070-4097

Ingrida VIŠINSKAITE் is a Master's student of Accounting and Auditing at Kaunas University of Technology, School of Economics and Business.

ORCID: 0000-0002-9568-8762

Register for an ORCID ID:

https://orcid.org/register

Copyright (C) 2020 by author(s) and VsI Entrepreneurship and Sustainability Center

This work is licensed under the Creative Commons Attribution International License (CC BY). http://creativecommons.org/licenses/by/4.0/

(c) (i) Open Access 